\title{
III Congresso Internacional

\section{A BIOTECNOLOGIA EM LIVROS DIDÁTICOS DE BIOLOGIA DO ENSINO MÉDIO: ENSAIO DE UMA PROPOSTA METODOLÓGICA}

\author{
Apresentação: Comunicação Oral \\ César Henrique Pinto Moreira ${ }^{1}$; Simone Nascimento Anacleto²; José Kleber Virgínio da Silva²; \\ Flávia Carolina Lins da Silva ${ }^{3}$
}

\begin{abstract}
Resumo
Em busca de informações sobre a abordagem do tema Biotecnologia no Ensino de Biologia, iniciamos nossa pesquisa através da análise de livros didáticos. Aqui traçamos como objetivo analisar o espaço da abordagem do tema Biotecnologia em livros didáticos de Biologia aprovados pelo PNLD de 2015 de mesma autora para cada ano do Ensino Médio. Em razão da abrangência que envolve nosso tema de análise, optamos por estruturar nossa fundamentação teórica focando na história e impactos da Biotecnologia para melhor situarmos o tema e sua importância para a formação em Biologia na Educação Básica. A natureza de nossa pesquisa é do tipo quantitativaqualitativo de cunho descritivo interpretativo, que teve como instrumento de pesquisa uma ficha de análise elaborada em Excel 2010 para auxiliar no momento da avaliação em termos de: formas de apresentação, ocorrência por área de estudo da Biologia, temas e exemplos abordados e temas em potencial. Em termos de resultados, podemos afirmar que para cada ano do Ensino Médio, os temas e exemplos biotecnológicos relacionados ao paradigma clássico são mais explorados nos dois primeiros volumes da coleção, ao passo que o paradigma moderno da Biotecnologia, que envolve manipulação gênica, faz-se presente no último volume, em especial devido à presença do conteúdo Biologia Molecular. Além disso, percebe-se que há possibilidades para explorar temas da Biotecnologia em todos os anos do Ensino Médio. Desta forma, a coleção aqui analisada apresenta, apesar de defender uma concepção ampla de Biotecnologia, concentra este tipo de informação no último volume como parte de um capítulo do bloco de Biologia Molecular. O que nos leva a concluir que, no tocante à Biotecnologia, os livros didáticos dão muito enfoque a Biotecnologia Moderna.
\end{abstract}

Palavras-Chave: Ensino de Biologia, Ensino de Biotecnologia, transposição didática.

\section{Introdução}

$\mathrm{Na}$ atualidade, o papel do professor passa a ser compreendido como mediador da aprendizagem ao articular os conteúdos a serem ensinados presentes tanto no livro didático (LD) como em outras fontes de informações (artigos científicos e jornalísticos, por exemplo), objetivando a apropriação desse saber pelo aluno, tal processo faz parte de um todo maior conhecido como transposição didática (CHEVALLARD, 1991), que objetiva dá uma "nova cara" aos saberes científicos a serem utilizados pelas instituições de ensino, como é o caso das escolas.

\footnotetext{
${ }^{1}$ Mestrando em Ensino de Ciências, UFRPE. E-mail: cesarhpm.biologia@ outlook.com

${ }^{2}$ Licenciado em Ciências Biológicas, UFRPE. E-mail: simone_anacleto_@hotmail.com; kleber.jkv@gmail.com

${ }^{3}$ Professor Adjunto IV da Área de Ensino de Ciências Biológicas, UFRPE. E-mail: flaviaclds@gmail.com
} 
Desde o Programa Nacional do Livro Didático (PNLD), o LD passou a se constituir um recurso presente nas escolas públicas graças à ação do governo brasileiro que também avalia e coloca a disposição certo número de opções de livros, constituindo-se inclusive como referência e "selo de garantia" para as instituições particulares. Além disso, o LD pode ser visto como uma fonte segura ou bibliográfica tanto por alunos como professores. Sendo ainda para o professor um veículo de atualização, embora existam pesquisas que apontem para resistência por parte dos professores em aceitar plenamente o que é dito pelos LDs (NETO; FRANCALANZA, 2003).

Com relação aos conteúdos presentes nesta "fonte segura", pesquisas também já dão sinais de que há falhas nos conteúdos teóricos, recursos visuais, nas atividades propostas e também nas instruções direcionadas ao docente (LOPES; VASCONCELOS, 2012) e desarticulada com as demais áreas do conhecimento (GRAMOWSKI; DELIZOICOV; MAESTRELLI, 2014).

No entanto, novas informações são produzidas e necessitam ser contempladas no LD de modo a atualizar o campo de estudo, como é o caso da Biotecnologia. No entanto, os resultados produzidos por ela se apresentam à sociedade na maioria das vezes como temas bilaterais, pois dividem a opinião pública, como é o caso dos alimentos transgênicos e células-troncos. Sendo assim, reiteramos que o Ensino de Biologia deve priorizar essas questões em benefício à formação cidadã e serem tratados não como meros exemplos ou unicamente benéficos, mas de maneira crítica e reflexiva uma vez que permeia questões de natureza ética, filosófica e mesmo cultural e religiosa.

Deste modo, objetivamos analisar o espaço da abordagem do tema Biotecnologia em LD de Biologia de uma mesma autora para cada ano do Ensino Médio aprovado pelo PNLD 2015. Diante disso, nossa pesquisa se justifica por se tratar de uma temática tão em voga como a Biotecnologia e merece destaque para todo o Ensino de Biologia, e não somente ser discutido com relação aos conteúdos de Genética ou num capítulo a parte, uma vez que as atividades da Biotecnologia encontram espaço nos diversos campos da Biologia e, portanto, deve estar presente ao longo de toda formação do primeiro ao último ano do Ensino Médio.

\section{Fundamentação Teórica}

Os processos biotecnológicos vêm sendo utilizados pela humanidade desde a mais remota antiguidade. Teve início com as atividades de domesticação e seleção de vegetais e animais para consumo quando o homem abandona a vida nômade, e também com os processos fermentativos de bebidas alcoólicas já conhecidas pelas civilizações babilônicas e sumérias, umas das mais antigas da história. Depois vieram outras aplicações como a produção pães, vinagre, iogurte e queijos que são utilizadas pelo ser humano até os dias atuais. 
No entanto, não se tinha conhecimento do que ao certo causava as fermentações, o que viria a ser elucidada em 1876 quando Louis Pasteur provou que a causa das fermentações era a ação dos micro-organismos, sobrepondo a teoria vigente de que a fermentação era um processo essencialmente químico. Segundo Villen (2002), daí por diante aconteceram diversos marcos na Ciência com o advento da Revolução Industrial e guerras mundiais, como o desenvolvimento do primeiro antibiótico: a penicilina, descoberta em 1928 de modo acidental por Alexandre Fleming.

As atividades desse período configuram-se, nas palavras de Malajovich (2012), como a fase da Biotecnologia Clássica como aquela que é caracterizada pelas atividades de cultivo de vegetais, domesticação de animais, transformação dos alimentos ou uso de propriedades curativas oriundas de organismo ou parte dele. Entretanto, foi a partir da década de 50 que a Biotecnologia, com a descoberta da síntese química do ácido desoxirribonucleico (ADN), e com as técnicas de manipulação gênica como o $\mathrm{ADN}$ recombinante, que surge uma nova fase denominada de Biotecnologia Moderna.

Porém, vale frisar que muito do que comemos e utilizamos como medicamentos são obras da Biotecnologia. Grande parte da produção nacional de soja, milho e feijão são de organismos geneticamente modificados. A existência da produção de insulina por micro-organismos transgênicos que, até a década de 1980 era extraída de bois e porcos e com frequência causava alergias, hoje traz benefícios a diabéticos do mundo inteiro (MALAJOVICH, 2012).

O desenvolvimento de medicamentos no combate a Síndrome da Imunodeficiência Adquirida (SIDA) são exemplos da atuação da Biotecnologia na área da Saúde. No sabão em pó, por exemplo, enzimas - produzidas por bactérias geneticamente modificadas - são usadas para degradar a gordura dos tecidos e resistir às condições do processo de lavagem, facilitando nosso dia-a-dia e aprimorando a limpeza, conforme exemplifica o Conselho de Informações sobre Biotecnologia (CIB, 2015).

Através desses exemplos podemos perceber o quanto a Biotecnologia é atuante na nossa vida e que ela merece ter seu espaço no Ensino Básico, para que os novos membros da sociedade estejam munidos de informações para tratar desses assuntos e expor suas opiniões (XAVIER; FREIRE; MORAES, 2005).

Desde tempos passados quando surgiram os primeiros estudos sobre Biotecnologia, deramse várias explicações para o conceito dessa ciência. Malajovich (2012) revisitando os textos da década de 1980, anos em que a expressão "Biotecnologia" se expande, encontrou mais de uma dúzia de definições diferentes para o termo, mas observou que, com o tempo, o conceito ganha uma expressão mais simples: as definições mais recentes não fazem mais referência aos processos tecnológicos envolvidos. Concepção semelhante é divida por Albagli (1998), quando este afirma 
que o conceito de Biotecnologia por ser compreendido como qualquer técnica que se utilize de organismos vivos (ou partes), objetivando a produção ou modificação de bens; e mesmo aperfeiçoamento de plantas ou animais, e a descoberta de micro-organismos para usos específicos. Porém, para Borém (2005) a Biotecnologia do século XXI em muito se difere da Biotecnologia Clássica (antes da revolução no campo da Genética e da Biologia Molecular) não por causa de seus princípios envolvidos, mas pelas suas técnicas utilizadas uma vez que opera em nível molecular e celular transcendendo as barreiras estabelecidas na formação das espécies. Partindo dessa análise conceitual, aqui adotamos a definição de Biotecnologia defendida por Malajovich (2012, p. 2).

[...] consideraremos a biotecnologia de uma maneira ampla, definida como uma atividade baseada em conhecimentos multidisciplinares, que utiliza agentes biológicos para fazer produtos úteis ou resolver problemas. Esta definição é suficientemente abrangente para englobar atividades tão variadas como as de engenheiros, químicos, agrônomos, veterinários, microbiologistas, biólogos, médicos, advogados, empresários, economistas etc.

Ainda sobre a definição de Malajovich (2012), temos como exemplos de Biotecnologia produtos e soluções que tanto faz parte da Biotecnologia Clássica como a fermentação e a produção de rolhas de cortiça extraídas dos sobreiros, como da Biotecnologia Moderna como é o caso dos alimentos de origem de Organismos Geneticamente Modificados (OGM) e serviços de biorremediação em casos de acidentes ambientais. Devido a esta multidisciplinaridade de inserção da Biotecnologia, Xavier, Freire e Moraes (2005, p. 02) destacam a importância da inserção do Ensino de Biotecnologia nos estudos escolares:

Os temas que permeiam a Nova Biologia vêm se destacando, pois apresentam um grande apelo social, e interferem diretamente na vida das pessoas. Por isso, são conteúdos importantes a serem trabalhados na escola. Portanto, é imprescindível colocar nossos jovens em contato com esse conhecimento biotecnológico. Como então podemos conscientizar, preparar, envolver nossos jovens para tomada de decisões envolvendo questões como transgênicos, terapias gênicas, clonagem, células-tronco, teste de paternidade?

De igual modo, Malajovich (2012, p. 04) destaca a importância da Biotecnologia para a sociedade ao mencionar que:

Produtos e processos inimagináveis trinta anos atrás entram em nosso cotidiano antes que os alicerces científicos e tecnológicos correspondentes se insiram em nossa cultura, através de uma divulgação ampla que atinja também o sistema educativo em todos os seus níveis. Não existe possibilidade alguma de construir uma sociedade moderna se os seus integrantes ignorarem os aspectos mais gerais de ciência e tecnologia. O desconhecimento aumenta o risco de rejeitar tecnologias promissoras, capazes de abrir perspectivas novas, com vistas a um desenvolvimento sustentável em áreas tão críticas como a saúde, a produção de alimentos, a energia e o meio ambiente.

Dada à necessidade da inserção dos temas nos currículos escolares e do avanço da Biotecnologia, as escolas, assim como os professores, veem-se diante de mais um desafio a 
enfrentar: propiciar ao aluno situações para avaliar as vantagens e desvantagens dos avanços tecnológicos; enquanto que para os autores e editoras de materiais didáticos de integrá-los no corpus de saberes a serem ensinados como de fundamental importância para o desenvolvimento do pensamento crítico dos alunos.

Vale frisar que a participação do Brasil no mundo da Biotecnologia vem se destacado nos últimos anos, em especial no quesito publicação científica e patentes, segundo a Agência Brasileira de Desenvolvimento Industrial (ABDI, 2010). Desta forma, percebe-se que o futuro do Brasil na Biotecnologia tende a crescer, sendo igualmente necessária uma maior quantidade de pessoas formadas na área e para tal, o investimento tem de começar na Educação Básica, de modo a torná-la visível para os jovens e atraí-los para essa área.

As disciplinas que envolvem a área da Biotecnologia, segundo Faleiros e Andrade (2011), são: Bioquímica; Biologia Celular; Biologia Molecular; Genética Molecular; Engenharia Genética; Microbiologia Agrícola; Fitopatologia; Biomedicina; Genética e melhoramento; e Engenharia Química. Segundo estes mesmos autores, a Biotecnologia pode ser compreendida como uma ciência que incide principalmente na indústria, meio ambiente, saúde, agropecuária e também a área científica em diferentes profissões, sendo assim de natureza interdisciplinar e que tem trazido benefícios diversos à sociedade.

As aplicações da Biotecnologia na área industrial, ambiental, agropecuária, saúde e pesquisas (FALEIROS; ANDRADE, 2011) também compõem a economia mundial, além de perpassar por questões sociais a exemplo da Bioética, a exemplo disso temos: o uso de animais para atividades experimentais, e o abate de bois para consumo humano, por exemplo, temas que tem sido pouco recorrente nos meios de comunicação em massa.

Embora se desenhe um panorama positivo para a Biotecnologia, o uso do petróleo, por exemplo, como fonte de combustível e matéria-prima para diversos produtos é esquecida como um produto de origem biológica e que pode ser citado como uma Biotecnologia "ruim", ao passo que os avanços dos estudos em nanobiotecnologia como algo extremamente promissor. Essas questões que envolvem os processos biotecnológicos, a exemplo da extração da peçonha de uma serpente para produção de soro, e uso de derivados da maconha, são alguns exemplos que trazem à tona a dimensão reflexiva e crítica da Biotecnologia para o Ensino de Biologia.

Embora seja notória, a Biotecnologia é uma ciência em expansão e que vem promovendo profundas mudanças na sociedade dada sua quase "[...] ilimitada gama de aplicações tecnológicas" (SILVA; CAVALCANTI, 2014, p. 5079), mas pouco tem se percebido sua presença em sala de aula seja por falta de preparo do docente, de tempo para se trabalhar a "Nova Biologia" e/ou de material didático atualizado (XAVIER; FREIRE: MORAES, 2005), o que inclui não somente o 
texto principal do livro, mas outros elementos informativos como textos complementares, atividades, exercícios e, em especial, as imagens dada sua relação com a memória visual (FREITAS; BRUZZO, 1999).

O processo de inclusão dos conteúdos referentes à Biotecnologia nos livros didáticos de Biologia necessariamente passam pelo processo de atualização, mas sua inclusão não pode ser aleatória, ou como Silva e Frenedozo (2009, p. 3) afirmam: "Não se trata, contudo, de se incorporar elementos da ciência contemporânea, simplesmente por conta de sua importância instrumental utilitária, mas sim como instrumento capaz de propiciar aos alunos uma visão de mundo atualizada". E a Biotecnologia hoje se configura como um saber necessário para a formação educativa escolar em razão dos muitos produtos, serviços e ações humanas estarem relacionadas a ela, e que configura como uma necessidade para enfrentar os problemas futuros como a produção de alimentos, proteção de ambientes naturais entre outras.

\section{Metodologia}

Apesar da importância do paradigma qualitativo para as pesquisas da área de Educação e Ensino de Ciências, em nossa pesquisa utilizamos da abordagem predominantemente qualitativa, uma vez que "[...] existem fatos que são do domínio quantitativo e outros de domínio qualitativo" (OLVEIRA, 2005, p. 68), do tipo documental e descritivo interpretativo.

Para compor nossa amostra, selecionamos uma coleção de LD de Biologia de volume específico para cada ano escolar do Ensino Médio de mesma autoria aprovada pelo PNLD 2015. Dizemos amostra, visto que será analisada uma das coleções aprovadas no PNLD para a área de Biologia objetivando inferir como se dá a abordagem do conteúdo de Biotecnologia para o período estabelecido. O quadro 1 apresenta informações sobre a coleção que compõe nossa amostra. A coleção foi obtida na biblioteca de uma escola pública do Recife, sendo assim, nossa análise se debruça em livros já utilizados ou em fase de uso por vários alunos e professores de Biologia.

Quadro 1 - Livros didáticos da amostra da pesquisa e sua codificação. Fonte: Própria.

\begin{tabular}{|c|c|c|c|c|c|c|}
\hline PNLD & Editora & Autores & Coleção & Volume - Temas de estudo & Página & Código \\
\hline \multirow{3}{*}{2015} & \multirow{3}{*}{$\begin{array}{l}\text { Editora } \\
\text { AJS }\end{array}$} & \multirow{3}{*}{$\begin{array}{l}\text { V. L. } \\
\text { Mendonça }\end{array}$} & \multirow{3}{*}{ Biologia } & $\begin{array}{l}\text { v. } 1 \text { - Ecologia, Origem da vida e Biologia } \\
\text { Celular e Embriologia e Histologia }\end{array}$ & 320 & 015.1 \\
\hline & & & & v. 2 - Os seres vivos & 320 & PNLD2015.2 \\
\hline & & & & v. 3 - O ser humano, Genética e Evolução & 296 & PNLD2015.3 \\
\hline
\end{tabular}

Para realizarmos a identificação, classificação e análise dos conteúdos de Biotecnologia nos LD de Biologia aprovados pelo PNLD 2015, construímos uma planilha em Excel 2007 que nos auxiliasse no momento do levantamento das ocorrências de aspectos e informações relacionadas direta e indiretamente à Biotecnologia a partir dos seguintes itens: I - área da Biologia: ou seja, em 
que bloco temático a informação foram localizadas; II - Unidade de contexto: o trecho ou descrição dela associado com a página de sua localização; III - Paradigma da Biotecnologia: se a informação refere-se à Biotecnologia Clássica ou Moderna, ou ainda ambas; IV - Local de apresentação no livro: trata-se de identificar a forma como ela foi apresentada, seja ela no texto principal, elementos informativos, texto complementar, imagens e sua legenda, atividades práticas, e exercícios e atividades teóricas; também elencamos o item V - Informação com potencial, o qual se refere ao tema biotecnológico que poderia ser explorado naquele momento do livro em decorrência das informações ali exploradas, mas que não foi feita; VI - Tema/Exemplo: o tema ou exemplo biotecnológico explorado.

Desta forma, temos a intenção de fazer uma análise mais profunda e não fragmentada como tem sido usualmente feito sobre os LDs, quando só analisam o tema apenas no capítulo em que é abordado. E apesar de um dos livros apresentarem uma parte do capítulo dedicado para se abordar o tema Biotecnologia, optamos por analisar todos os volumes a fim de encontrar situações em que o tema em questão foi inserido e/ou poderia ser explorado.

\section{Resultados e Discussão}

Primeiramente, a análise geral da coleção nos permite afirmar que em termos de conteúdo teórico, o conteúdo de Biotecnologia é contemplado na coleção claramente num tópico do capítulo referente à Biologia Molecular do PNLD 2015.3. Além do espaço reservado para a apresentação do texto principal, encontramos ao longo dos capítulos caixas de textos ou elementos informativos, com a finalidade de comentar sobre algumas curiosidades do tema, ou mesmo indicações de atividades ou novidades do campo científico sempre apresentadas próximas ao texto principal assim como as imagens, além de: textos para leitura presentes no final de cada capítulo (aqui compreendido como texto complementar); questões próprias do livro, de vestibulares (incluindo-se as do Exame Nacional do Ensino Médio - ENEM), e também estruturadas na perspectiva Ciência, Tecnologia e Sociedade (CTS).

No total foram detectados 128 trechos ou unidades referentes ou alusivos à Biotecnologia, destas 28\% são referentes à Biotecnologia Clássica, com temas referentes a produtos alimentares, domesticação de plantas e animais (cruzamento seletivo), produtos comerciais de origem animal como mel e botões de madrepérola; enquanto que $73 \%$ atinentes à Biotecnologia Moderna, que exploravam o tema antibiótico, vacina, soro (medicamento), célula-tronco, OMG e transgênicos. As unidades encontradas na coleção do PNLD 2015 estão distribuídas em diferentes formas de apresentação e em diferentes áreas do conteúdo de Biologia conforme o gráfico 1 ilustra. 
Gráfico 1 - Frequência absoluta das unidades de análise sobre Biotecnologia quanto à localização no livro (à esquerda) e por área da Biologia (à direita). Fonte: Própria.

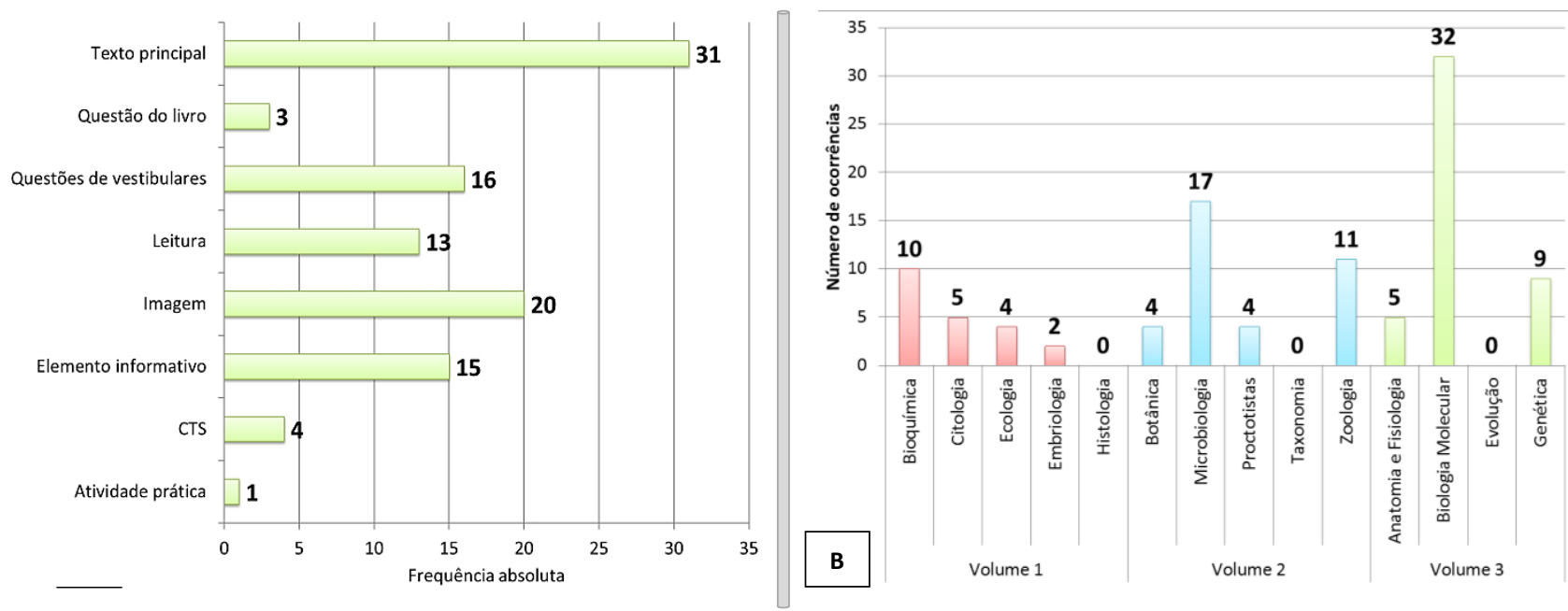

O que se percebe é que boa parte das informações sobre biotecnologia foram encontradas no texto principal, sendo que das 31 unidades detectadas 13 delas no bloco de Biologia Molecular, ou seja, aproximadamente $42 \%$ das informações se concentram no último volume da coleção. Além disso, conforme o esperado, percebemos que este mesmo bloco de conteúdo concentra a maior quantidade de imagens (seis unidades) e questões de vestibulares (oito unidades).

Outra informação importante são as unidades encontradas na forma de Leitura, ou seja, àqueles que englobam os textos complementares, presente em maior concentração no bloco de Microbiologia (31\%). Estes textos buscaram englobar temas diversos como, por exemplo, o uso de células-tronco na Medicina, a história da domesticação de plantas, técnicas biotecnológicas, e outros que levassem a demonstrar as informações biológicas de forma aplicada em diferentes contextos. Deste modo, estes textos possibilitam aos professores de Biologia, conforme Xavier, Freire e Moraes (2005), levaram os jovens entrarem em contato com temas da Nova Biologia.

À luz das informações no gráfico $1 \mathrm{~A}$, percebe-se que a soma de informações oriundas das imagens, questões de vestibular e elementos informativos (total de 51 unidades) superar a soma de unidades encontradas no texto principal e para leituras (44 unidades). Este dado se mostra preocupante, visto que o potencial das informações apresentadas neste conjunto maior está voltado para detalhar sobre os procedimentos biotecnológicos, e quase nunca para suas implicações sociais e ambientais. Portanto, a valorização deste conjunto de informações se mostra de pouco impacto por não possibilitarem o desenvolvimento de processos metacognitivo como o refletir e argumentar, a exceção das questões elaboradas na perspectiva CTS.

Outra informação que podemos extrair provém do gráfico 1B. Nela observamos que existem áreas da Biologia que por estarem fortemente relacionadas com a Biotecnologia, conforme cita Faleiros e Andrade (2011) com a exceção da Biologia Molecular, também apresentaram uma grande 
quantidade de informações biotecnológicas como foi o caso da Bioquímica, abordada no primeiro volume da coleção, e da Microbiologia, abordada no segundo volume da coleção, mas até que a própria Genética.

O quadro 2 apresenta a lista de temas ou exemplos biotecnológicos encontrados nos livros analisados e percebemos que muitos dos temas da contemporaneidade, portanto da Biotecnologia Moderna, encontram-se no texto complementar ou principal, ao passo que muitos dos exemplos foram encontrados em questões de vestibular ou de maneira pontual no texto principal.

Quadro 2 - Temas ou exemplos citados constatados na análise dos livros didáticos do Ensino Médio. Fonte: Própria.

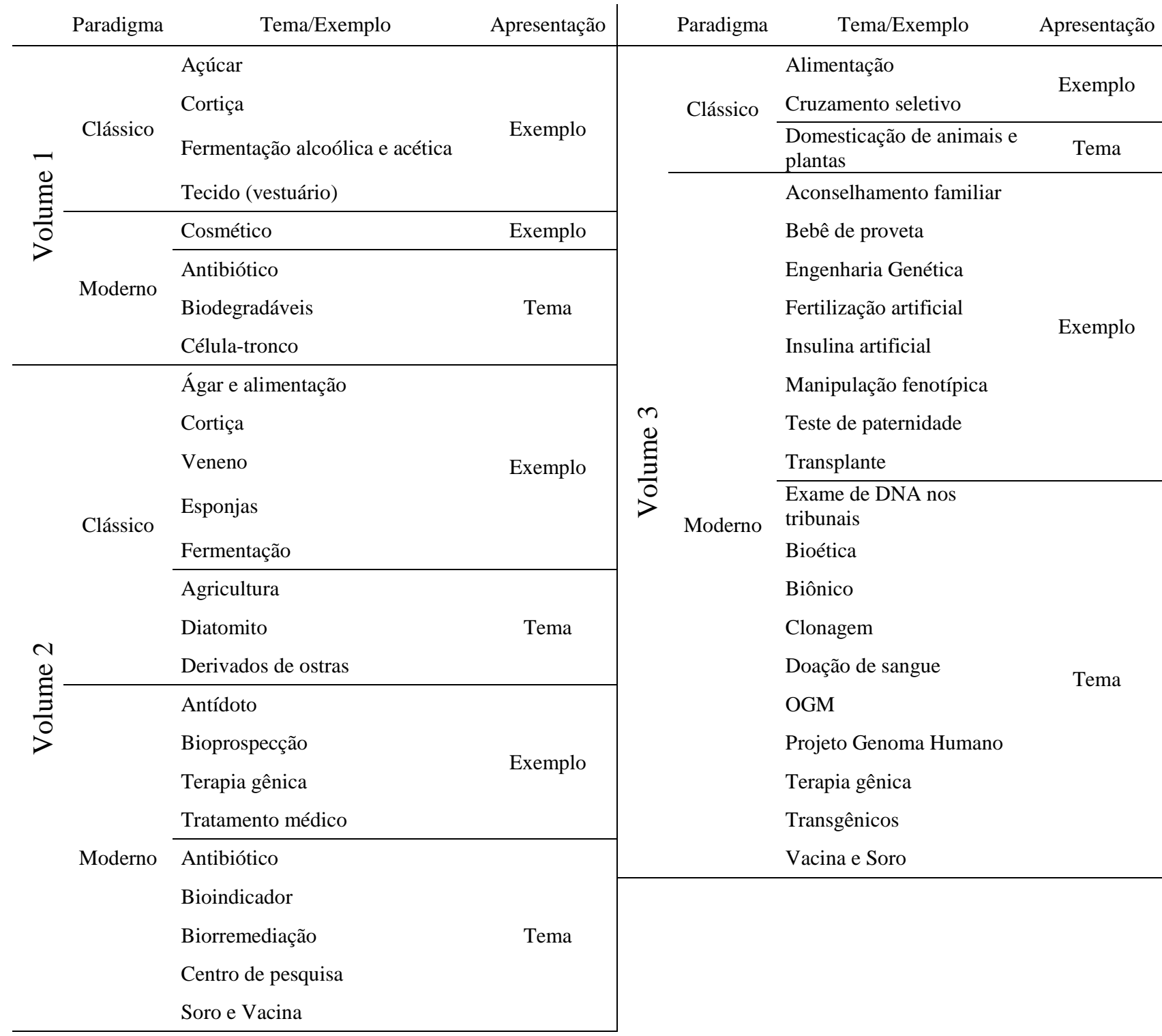

É interessante perceber que as informações da coleção permitem ao docente passear desde temas clássicos como a domesticação de animais e plantas e transgênicos, como as mais atuais como a da Bioinformática ao tocar na questão de biônicos e mesmo de biorremediação. 
Vale lembrar a recomendação dada por Malajovich (2012, p. 04), a de que "Não existe possibilidade alguma de construir uma sociedade moderna se os seus integrantes ignorarem os aspectos mais gerais de ciência e tecnologia". Isto significa que cabe ao professor de Biologia buscar meios de valorizar as informações produzidas, e que estão a serviço de toda a sociedade, produzidas pelas Ciências Biológicas dentro da sala de aula, como uma forma de superar o modismo já estabelecido pelo apego ao ensino conceitual e relacional das ciências. Basta lembrar que a Biotecnologia envolve diferentes conteúdos da Biologia ensinadas nas escolas e que estão presentes em diferentes atividades econômicas (FALEIROS; ANDRADE, 2011).

Quanto à definição de Biotecnologia detectado em PNLD2015.3 afirma que: "O termo biotecnologia resulta da união de bio (vida), techn (técnicas) e logos (estudo). Assim, essa é a área de estudo das técnicas que utilizam seres vivos para a obtenção de produtos de interesse humano. Essas técnicas resultam na modificação de seres vivos, com determinadas finalidades" (MENDONÇA, 2013, p. 231). Quando alega se tratar de técnicas que resultam na modificação dos seres vivos para obter produtos de interesse humano, observamos que esta concepção se aproxima daquela defendida por Malajovich (2012) e Albagli (1998), que reconhecem os dois paradigmas da Biotecnologia, as quais poderiam ter sido mais bem exploradas na coleção, conforme sugerimos e listamos no quadro 3 a seguir, seja compondo o livro didático seja como temas que os professores podem explorar.

Quadro 3 - Temas biotecnológicos que poderiam ser explorados. Fonte: Própria.

\begin{tabular}{|c|c|c|c|}
\hline Volume & Área & Paradigma & Tema \\
\hline \multirow{5}{*}{$\begin{array}{l}\stackrel{ }{\rightleftarrows} \\
\stackrel{\partial}{\supset}\end{array}$} & Bioquímica & Clássica & $\begin{array}{l}\text { - } \text { Celulose } \\
\text { - Etanol e outros derivados da cana-de-açúcar } \\
\text { - Fermentação Lática } \\
\text { - Produtos gerados pelas abelhas }\end{array}$ \\
\hline & Citologia & Moderna & - Consumo de produtos ricos em colágeno \\
\hline & Ecologia & $\begin{array}{l}\text { Clássica } \\
\text { Moderna }\end{array}$ & $\begin{array}{l}\text { - } \quad \text { Compostagem } \\
\text { - } \quad \text { Biorremediação }\end{array}$ \\
\hline & Embriologia & Moderna & - $\quad$ Fertilização artificial \\
\hline & Histologia & Moderna & $\begin{array}{l}\text { - Hemoderivados } \\
\text { - } \quad \text { Síntese de tecidos biológicos para fins medicinais }\end{array}$ \\
\hline \multirow{2}{*}{$\stackrel{\stackrel{\Perp}{ٍ}}{\stackrel{一}{\supset}}$} & Botânica & $\begin{array}{l}\text { Clássica } \\
\text { Moderna }\end{array}$ & $\begin{array}{l}\text { - } \quad \text { Biocombustível de turfa } \\
\text { - } \quad \text { Novas variedades de flores comerciais }\end{array}$ \\
\hline & Zoologia & Clássica & $\begin{array}{l}\text { - } \quad \text { Produtos gerados pelas abelhas } \\
\text { - O uso da tinta preta extraída de moluscos } \\
\text { - } \quad \text { Extração de veneno para diversos fins }\end{array}$ \\
\hline \multirow[t]{3}{*}{ 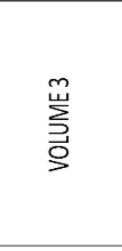 } & $\begin{array}{l}\text { Anatomia e } \\
\text { Fisiologia } \\
\text { Humana }\end{array}$ & Moderna & $\begin{array}{l}\text { - Seres Biônicos: próteses da bioinformática } \\
\text { - Enzimas como produtos industriais } \\
\text { - Fertilização artificial } \\
\text { - Hemoderivados } \\
\text { - Hormônios bioidênticos }\end{array}$ \\
\hline & Evolução & Clássica & - Pele de animais como vestuário \\
\hline & Genética & Moderna & - Engenharia Genética \\
\hline
\end{tabular}

Quanto aos elementos que poderia ter sido abordado, destacamos o tema biônico e célulatronco. Apesar de está presente apenas no livro PNLD2015.2, o tema biônico (próteses modernas) 
pouco é explorado, apresentado informações mais direcionada à locomoção, esquecendo-se de informar que hoje já se dispõe de olhos e ouvidos biônicos, por exemplo. Da mesma forma acontece com o tema célula-tronco e bioética: o primeiro apresentado como texto complementar em PNLD2015.1, e o outro na forma de uma proposta de pesquisa em PNLD2015.3 no capítulo de Biologia Molecular. Este e outros temas poderiam ser abordados ou na forma de um texto complementar ou mesmo pesquisa, mas que fizessem parte e com maior destaque já que são temas que dividem a opinião pública e também envolve a questão da bioética.

\section{Conclusões}

A coleção aqui analisada apresenta grande parte das informações referentes à Biotecnologia concentrada no bloco de Biologia Molecular, no último volume da coleção (PNLD 2015.3), como era de se esperar. O que nos leva a concluir que, no tocante à Biotecnologia, os livros didáticos dão muito enfoque a Biotecnologia Moderna. Os impactos da Biotecnologia na sociedade contemporânea vêm mostrando o quanto é importante inserir este tema na formação em Biologia dos estudantes da Educação Básica. Desta forma, destacamos a necessidade dos livros didáticos atualizarem e ampliarem seus conteúdos, dando atenção à contextualização, para promover novas estratégias e assim adicionar os temas modernos que surgiram no decorrer da história humana.

\section{Referências das obras analisadas}

MENDOÇA, V. L. Biologia: ecologia, origem da via e biologia celular e embriologia e histologia. 2. ed. São Paulo: Editora AJS, 2013. v. 1.

. Biologia: o ser humano, genética, evolução. 2. ed. São Paulo: Editora AJS, 2013. v. 3.

. Biologia: os seres vivos. 2. ed. São Paulo: Editora AJS, 2013. v. 2.

\section{Referências}

AGÊNCIA BRASILEIRA DE DESENVOLVIMENTO INDUSTRIAL. Biotecnologia: Iniciativa Nacional de Inovação. Panorama da biotecnologia no mundo e no Brasil. Brasília: ABDI, 2010.

ALBAGLI, S. Da biodiversidade à biotecnologia: a nova fronteira da informação. Revista Ciências da Informação, Brasília, Brasil, v. 27, n. 1, p. 7-10, jan./abr. 1998.

CAVAGNOLI, S. R.; SOARES, M. A. M. Desmistificando a biotecnologia. 200?. Disponível em: $<$ http://www.gestaoescolar.diaadia.pr.gov.br/arquivos/File/producoes_pde/artigo_sonia_regina_cav agnoli.pdf>. Acesso em: 25 set. 2016. 
CHEVAlLARD, Y. La Transposición Didáctica: Del saber sabio al saber enseñado. Buenos Aires, Argentina: Aique, 1991.

CONSELHO DE INFORMAÇÕES SOBRE BIOTECNOLOGIA. Biotecnologia: outras áreas. Conselho de Informações sobre Biotecnologia, São Paulo, 2015. Disponível em: <http://cib.org.br/biotecnologia/outras-areas/>. Acesso em: 25 set. 2016.

FALEIRO, F.G; ANDRADE, S. R. M. Biotecnologia: uma visão geral. In: FALEIRO, F. G.; Andrade, S. R. M. de; JUNIOR, F. B. dos R. Biotecnologia: estado da arte e aplicações na agropecuária. Planaltina, Distrito Federal: Embrapa Cerrados, 2011, p. 12-29.

FREITAS, D. S.; BRUZZO, C. As imagens nos livros didáticos de biologia. In: II Encontro Nacional de Pesquisa em Educação em Ciências, 1999, Valinhos - São Paulo. Atas do Encontro Nacional de Pesquisa em Educação em Ciências, 1999.

GRAMOWSKI, V. B.; DELIZOICOV, N. C.; MAESTRELli, S. R. P. O livro didático: a fragmentação dos conteúdos das ciências naturais. Revista SBEnBio, Rio de Janeiro, n. 7, p. 73127323 , out. 2014.

LOPES, W. R.; VASCONCELOS, S. D. Representação e distorções conceituais do conteúdo "filogenia" em livros didáticos de biologia do ensino médio. Revista Ensaio, Belo horizonte, v. 14, n. 3, p. 149-165, set./dez. 2012.

MALAJOVICH M. A. Biotecnologia 2011. Rio de Janeiro: Edições da Biblioteca Max Feffer do Instituto de Tecnologia ORT, 2012.

OLIVEIRA, M. M. de. Como fazer pesquisa qualitativa. Recife: Bagaço, 2005.

SILVA, L. C. da H.; CAVALCANTI, D. P. DNA e suas aplicações biotecnológicas: uma análise da aprendizagem de professores da educação básica. Revista SBENBio, Rio de Janeiro, n. 7, p. 50795091, out. 2014.

SILVA, R. da; FRENEDOZO, R. de C. Mudanças e simplificações do saber científico ao saber a ensinar: uma análise da transposição didática do ciclo do nitrogênio em livros didáticos de biologia do ensino médio. In: VII Encontro Nacional de Pesquisa em Educação em Ciências, 2009, Florianópolis. Atas do Encontro Nacional de Pesquisa em Educação em Ciências, 2009.

VASCONCELOS, S. D.; SOUTO, E. O livro didático de ciências no ensino fundamental - proposta de critérios para análise do conteúdo zoológico. Revista Ciências e Educação, Bauru, São Paulo, v. 9, n. 1, p. 93-104, 2003.

VILLEN, R. A. Biotecnologia: histórico e tendências. Revista de Graduação da Engenharia Química, São Caetano do Sul, São Paulo, v. 5, n. 10, jul./dez. 2002.

XAVIER, M.C.; FREIRE, A.S.; MORAES, M.O. A introdução dos conceitos de biologia molecular e biotecnologia no ensino de genética no nível médio. Há espaço para a Nova Biologia? In: V Encontro Nacional de Pesquisa em Educação em Ciências, 2005, Bauru - São Paulo. Atas do Encontro Nacional de Pesquisa em Educação em Ciências, 2005. 